\title{
Histopathological evaluation of Non-Neoplastic and Neoplastic Lesions of Uterine Cervix at tertiary care centre
}

\author{
Supriya B.R $\mathbf{R}^{1}$, Patel $\mathbf{R}^{2}$, Patel $\mathbf{M}^{3}$ \\ ${ }^{1}$ Dr. Supriya B.R., Consultant, Pathologist, Radon Cancer Centre, Hubli, Karnataka, ${ }^{2}$ Dr. Ragini Patel, Tutor, Pathology \\ Department, GMERS Medical College, Valsad, Gujarat, ${ }^{3}$ Dr. Manisha Patel, Associate Professor, Pathology Department, \\ Baroda Medical College, Vadodara, Gujarat, India.
}

Corresponding Author: Dr. Ragini Patel, Tutor, Pathology Department, GMERS Medical College, Valsad, Gujarat, India. Email: rags3276@gmail.com

\begin{abstract}
Background: Uterine cervix is common specimen from gynecological department with non-neoplastic and neoplastic lesions. Most cervical cancers can be detected at pre-invasive state with an adequate screening and treated appropriately thus preventing overt progression to full blown cancer and hence decreasing morbidity and mortality. Carcinoma of cervix is a preventable tumor and if good effort given in detecting preinvasive lesion one can give definite treatment at earliest. Objectives: To evaluate the histopathological diagnosis of a biopsy of cervix in women with unhealthy cervix. Also, to study the agerelated, incidence and the incidence of various nonneoplastic and neoplastic lesions of the cervix. Methodology: It is a cross sectional study. Institutional Ethics committee permission was taken prior to start of the study. Pertinent clinical history like age, significant family and personal history, history of other diseases was taken. Cervical biopsy specimens collected from histopathology section and grading of cervical lesions was done based on the proportion of stained cells and the intensity of staining. Statistical analysis was done. The data were tabulated and frequencies and percentages were calculated. Observations: The common age group was 41-50 years (37.50\%) followed by 31-40 years of age (26.25\%). The symptoms with which patients presented were vaginal bleeding $(52.50 \%)$ followed by white discharge per vagina $(16.25 \%)$ and menorrhagia $(12.50 \%)$. The premalignant lesions were seen in 12 cases $(15.0 \%)$ and malignant lesions in 68 cases (85.0\%). Among them 64 malignant tumours were epithelial in origin. As per microscopic examinations squamous cell carcinoma was diagnosed in 61 cases $(93.75 \%)$, followed by 2 cases $(3.13 \%)$ of adenocarcinoma, and 1 case (1.58\%) of adenosquamous carcinoma and 1 case (1.54\%) of rhabdomyosarcoma. Conclusion: Cervical cancer continues to be the most common cancer of females in developing countries. One of the most significant advances in the management of cervical neoplasms has been the realization that cervical intraepithelial lesions behave as progressive stages of a biologic continuum towards the development of invasive cancer.
\end{abstract}

Keywords: Cervical Lesions, Non-neoplastic and neoplastic, Cervical carcinoma

\section{Introduction}

Among specimens from gynecological department, uterine cervix is most common with non-neoplastic and neoplastic lesions. The non-neoplastic cervical lesions are common in the women of reproductive age group. While cervix cancer is the third most common cancer in women worldwide and most common female cancer in many developing countries like India [1]. The histopathological specimens are from gynecological department and includes predominantly inflammatory and nonneoplastic tumor-likelesions such as cervical tunnel clusters, mesonephric and diffuse laminar hyperplasia, endometriosis, and micro glandular

Manuscript received: $4^{\text {th }}$ March 2019

Reviewed: $14^{\text {th }}$ March 2019

Author Corrected: $20^{\text {th }}$ March 2019

Accepted for Publication: $26^{\text {th }}$ March 2019 endocervical hyperplasia which simulates neoplasia are not much emphasized, hence identification of these lesions require familiarity in their histopathological features which is a prerequisite for proper management. Therefore, the histopathological evaluation is of paramount importance in diagnosing non-neoplastic and also neoplastic cervical lesions.

The precancerous state like cervical intraepithelial neoplasia (CIN) can be evaluated by cervical epithelium. Most cervical cancers can be detected at preinvasive state with an adequate screening and treated appropriately thus preventing overt progression to full blown cancer and hence decreasing morbidity and mortality [2]. Despite the implementation of Pap test 
that has successfully brought dramatic reduction in the incidence and mortality worldwide caused by cervical cancer, there are still a substantial amount cervical cancer occurring in women who are adequately screened, proving diagnostic limitation of the Pap test [3].

Carcinoma of cervix is a preventable tumor and if good effort given in detecting preinvasive lesion one can give definite treatment at earliest [4]. Also, because of its slow progression from precancerous lesion to malignancy and easy accessibility to examination, carcinoma of cervix had early detection opportunity and considerably improved prognosis $[5,6]$.

This study was conducted to evaluate the histopathological diagnosis of a biopsy of cervix in women with unhealthy cervix. Also, to study the age-related incidence and the incidence of various nonneoplastic and neoplastic lesions of the cervix.

\section{Materials and Methods}

Setting and Type of study: This is a cross sectional study of single group conducted by the Department of pathology S.S.G Hospital \& Medical College Baroda, Gujarat from June 2016 till December 2016.

Ethical consideration: Approval was obtained from scientific advisory committee and Institutional Ethics committee prior to start of the study. Subjects were enrolled in the study based on inclusion and exclusion criteria.

\section{Results}

Cases were enrolled over a period of seven months. During this study period a total of 80 cervical biopsies were received in the department of pathology and premalignant and malignant lesions of Cervix was studied in 80 cases.

Age distribution of the patients was ranged from 25 to 80 years. Highest numbers of patients were in the group of 41-50 years $(37.50 \%)$ followed by $31-40$ years of age $(26.25 \%)$ [Table 1 ].

The commonest symptoms with which the patients presented was vaginal bleeding $(52.50 \%)$ followed by white discharge per vagina (16.25\%) and menorrhagia (12.50\%) [Table 2]. The most common clinical diagnosis in this study was carcinoma cervix $(82.5 \%)$ followed by chronic cervicitis $(7.5 \%)$ [Figure 1 ].

Table-1: Age wise distribution of all cases of cervical lesions.

\begin{tabular}{|c|c|c|}
\hline Age group & Number of cases & Percentage \\
\hline $21-30$ & 3 & $3.75 \%$ \\
\hline $31-40$ & 21 & $26.25 \%$ \\
\hline $41-50$ & 30 & $37.50 \%$ \\
\hline $51-60$ & 12 & $15.00 \%$ \\
\hline $61-70$ & 12 & $15.00 \%$ \\
\hline $71-80$ & 2 & $2.50 \%$ \\
\hline Total & $\mathbf{8 0}$ & $\mathbf{1 0 0 . 0 0 \%}$ \\
\hline
\end{tabular}


Table-2: Clinical presentation of all cases cervical lesions.

\section{Original Research Article}

\begin{tabular}{|c|c|c|}
\hline Clinical Features & Number of cases & Percentage \\
\hline White Discharge Per Vagina & 13 & $16.25 \%$ \\
\hline Bleeding Per Vagina & 42 & $52.50 \%$ \\
\hline Menorraghia & 10 & $12.50 \%$ \\
\hline Abdominal Pain & 8 & $10.00 \%$ \\
\hline Cervical Growth & 5 & $6.25 \%$ \\
\hline Irregular Menses & 1 & $1.25 \%$ \\
\hline Cervical Descent & 1 & $1.25 \%$ \\
\hline Total & $\mathbf{8 0}$ & $\mathbf{1 0 0 . 0 0 \%}$ \\
\hline
\end{tabular}

Table-3: Age Wise Distribution of Patients with Cervical Carcinoma.

\begin{tabular}{|c|c|c|}
\hline Age group & Number of cases & Percentage \\
\hline $21-30$ & 2 & $3.13 \%$ \\
\hline $31-40$ & 18 & $28.13 \%$ \\
\hline $41-50$ & 23 & $35.94 \%$ \\
\hline $51-60$ & 9 & $14.06 \%$ \\
\hline $61-70$ & 10 & $15.63 \%$ \\
\hline $71-80$ & 2 & $3.13 \%$ \\
\hline Total & $\mathbf{6 4}$ & $\mathbf{1 0 0 . 0 0 \%}$ \\
\hline
\end{tabular}

Table-4: Clinical presentation ofcases of cervical carcinoma.

\begin{tabular}{|c|c|c|}
\hline Clinical Features & Number of cases & Percentage \\
\hline White Discharge Per Vagina & 10 & $15.63 \%$ \\
\hline Bleeding Per Vagina & 33 & $51.56 \%$ \\
\hline Menorraghia & 7 & $10.94 \%$ \\
\hline Abdominal Pain & 7 & $10.94 \%$ \\
\hline Cervical Growth & 5 & $7.81 \%$ \\
\hline Irregular Mensus & 1 & $1.56 \%$ \\
\hline Cervical Descent & 1 & $1.56 \%$ \\
\hline Total & $\mathbf{6 4}$ & $\mathbf{1 0 0 . 0 0 \%}$ \\
\hline
\end{tabular}
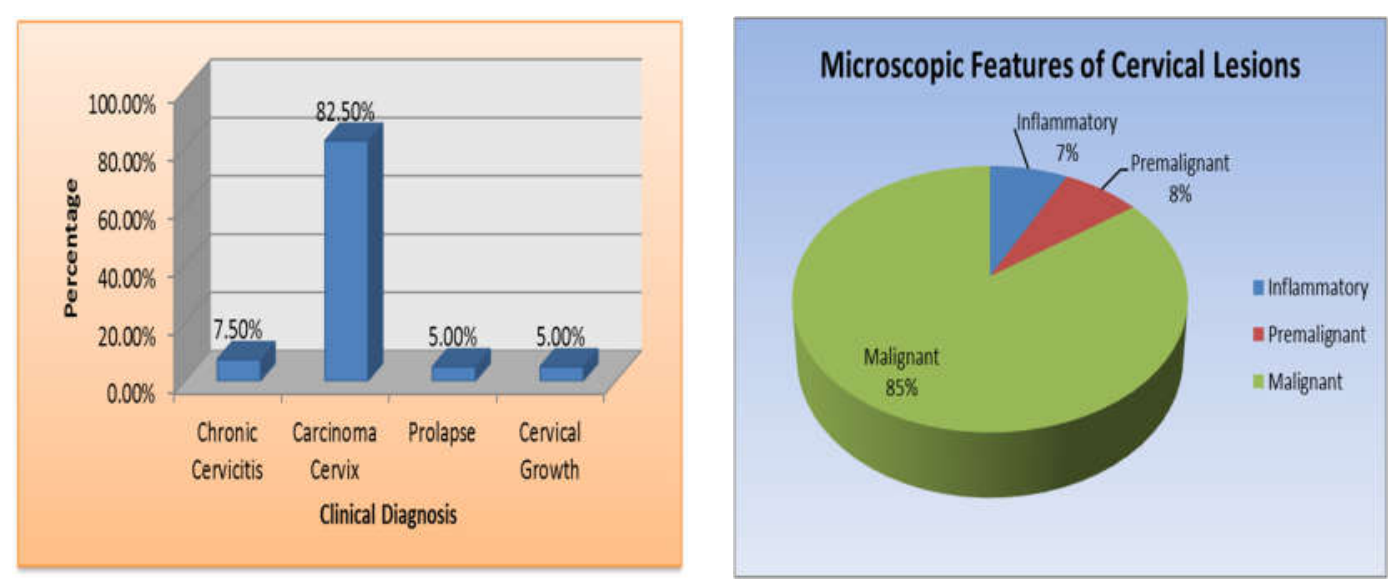

Fig-1 Clinical Diagnosis of all case of cervical lesions Fig-2: Microscopic features of all cervical lesions 


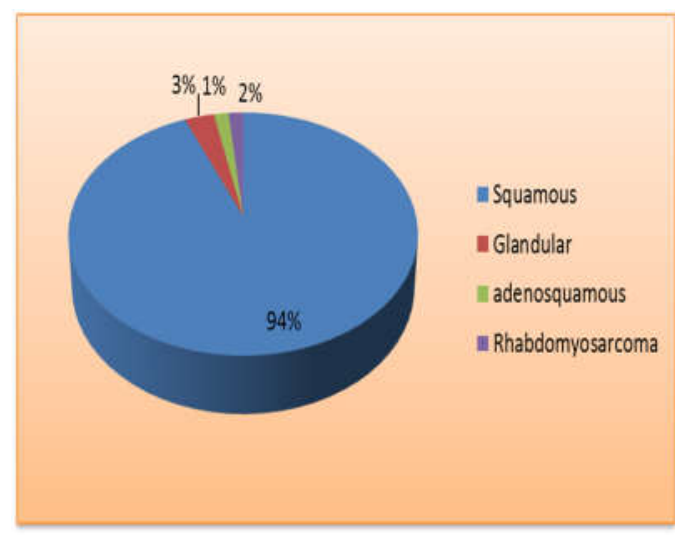

Fig-3: Type of invasive carcinoma

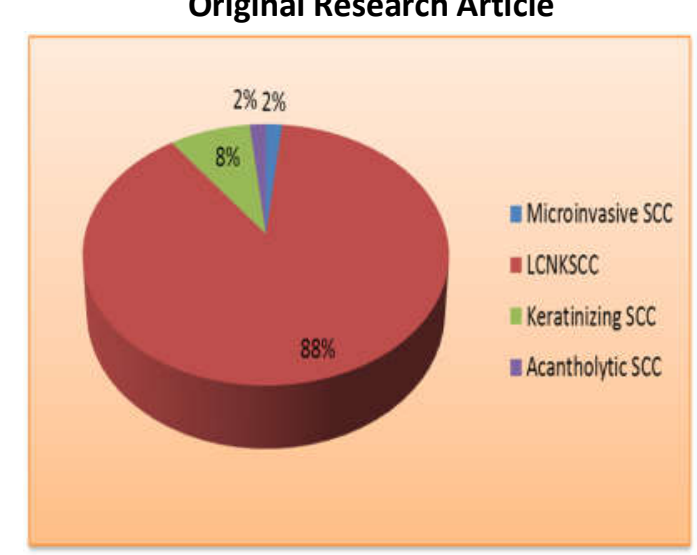

Fig-4: Distribution of histologic types of squamous cell carcinoma

Cervical biopsies of all 80 cases were studied. Gross feature shows largest measured $2.5 \mathrm{cms}$ in diameter and smallest measured $<0.5 \mathrm{cms}$. All were grey brown to grey white in appearance. Figure 2 shows the microscopic features of all cervical lesions. It shows that premalignant lesions were seen in 12 cases (15.0\%) and malignant lesions in 68 cases (85.0\%). Age wise distribution of the patients with cervical carcinoma showed that it ranged from 30 years to 76 years with a mean age of 48.6 years. Majority of the patients were in the 4th and 5th decade of life [Table 3]. Clinical presentation of patients with cervical carcinoma shows that 33 patients $(51.56 \%)$ were presented with complained of bleeding per vagina, and $10(15.63 \%)$ patients also had white discharge per vagina.

All the 64 malignant tumours were epithelial in origin. 1 case (1.54\%) was microinvasive carcinoma and other 63 cases (98.7\%) were invasive. As per microscopic examinations squamous cell carcinoma was diagnosed in 61 cases (93.75\%), followed by 2 cases (3.13\%) of adenocarcinoma, and 1 case (1.58\%) of adenosquamous carcinoma and 1 case (1.54\%) of rhabdomyosarcoma [Figure 3] of the 61 cases of squamous cell carcinoma, 1 case $(1.67 \%)$ was microinvsive squamous cell carcinoma, 54 (88.33\%) cases were large cell non keratinizing type (LCNK), $5(8.33 \%)$ cases were keratinizing type and $1(1.67 \%)$ case was acantholytic squamous cell carcinoma [Figure 4].

\section{Discussion}

Cervical carcinoma is the most common cancer in Indian women. It is a leading cause of death in women worldwide and develops from cervical intraepithelial neoplasia [7]. A preneoplastic cervical intraepithelial neoplasia can regress, persist or progress towards invasive carcinoma. Thus, the goal cervical cancer prevention program is to detect and treat all cancer precursors before invasion develops $[7,8]$. Cancer of the cervix is an important disease because of apparent frequency in women of low socioeconomic group. Exact incidence and death rate is difficult to state as it varies with community, age and stage of cancer [9].

The incidence of cervical carcinoma is highly dependent on age [10]. Mean age at diagnosis of invasive carcinoma in the present study was 48.46 years. A similar mean age of 47 years has been observed for diagnosis in the United States [10]. In a study conducted in central India mean age at diagnosis was 46.20 years [11]. Age range of patients in this study was 30 to 76 years with majority of cases $(66.2 \%>)$ in the 4th and 5th decade of life. These findings are comparable with other studies $[9,12]$.
The major symptoms associated with carcinoma cervix described by various authors are irregular bleeding per vaginum, foul smelling and blood stained white discharge, pain abdomen and cachexia [11]. Bleeding per vaginum was the most common presenting symptom in $50 \%$ of the women, followed by white discharge per vagina in $16 \%$ in the present study. In a study of cervical cancer amongst rural women in central India, Chhabra $\mathrm{S}$ et al [11] observed vaginal bleeding as most common symptom (32.15\%) and that women with more advanced disease presented with abnormal vaginal bleeding $(27.5 \%)$.

Microscopic examination of the biopsy showed Squamous cell carcinoma was the commonest diagnosis. It was diagnosed in $60(93.75 \%)$ cases, including $1(1.5 \%)$ case microinvasive carcinoma, $2(3.13 \%)$ cases of Adenocarcinoma 1(1.58\%) case of adenosqumous and $1(1.54 \%)$ case rhabdomyosarcoma. The incidence of different types of cervical malignancies in the present study is in accordance with other studies [10-14] Microinvasive squamous cell carcinoma has been a subject associated with decades of 
confusion, a multiplicity of definitions and a variety of therapeutic approaches [15]. In the present study microinvasive carcinoma was diagnosed in 1 case $(1.6 \%)$ of the 60 squamous cell carcinoma. The patient was aged 35 years and multiparous. Microscopy showed large cell non keratinising squamous cell carcinoma with depth of invasion less than $5 \mathrm{~mm}$ and moderate inflammatory infiltrate in the cervical stroma. Similar to our study, large cell nonkeratinizing type was the commonest morphological type of microinvasive carcinoma observed by van Nagell JR [16]. They found stromal invasion between $3.1 \mathrm{~mm}$ to $5 \mathrm{~mm}$. Most $(81.9 \%)$ tumours showed mild degree of inflammatory infiltrate in cervical stroma and lympho vascular invasion was absent in most (81\%) of their cases.

Out of 60 invasive squamous cell carcinomas studied, large cell non keratinizing type was the commonest seen in 54 cases $(88.52 \%)$. Keratinizing type was seen in 5 cases $(8.20 \%)$. Acantholytic squamous cell carcinoma was seen in 1 case $(1.64 \%)$. The observation regarding the predominant cell type of squamous cell carcinoma correlates with the study by Lowe D et al [11] who had also observed LCNK SCC as the commonest histological type of squamous cell carcinoma. Associated CIN was seen in 51 cases $(85 \%)$ of a total of 60 invasive squamous cell carcinoma. Similar findings have been reported by Primary adenocarcinoma of the cervix is an unusual lesion.

It is cytologically evasive, diagnostically challenging, histologically variable and therapeutically perplexing [17] In the present study, 2(3.13\%) cases of adenocarcinoma were seen of the total malignant tumours diagnosed in the cervical biopsies. This observation on the incidence of adenocarcinoma correlated with Momthahen $\mathrm{S}$ et al who had studied $74(8.1 \%)$ cases of cervical adenocarcinoma [10] In recent years it has been suggested that there has been a relative and absolute increase in the incidence of adenocarcinoma of the uterine cervix as shown in studies of Chen J et al, [14] which was done on a large population based database.

Adenosquamous carcinomas account for approximately $10 \%$ of all cervical cancers. These tumours were initially classified as a subtype of adenocarcinoma, but the present World Health Organization classification labels these tumors separately [18]. In the present study, one case $(1.54 \%)$ was diagnosed as adenosquamous carcinoma on cervical biopsy. These findings are similar to Lowe D et al [12] who reported 4 cases $(0.8 \%)$ of adenosquamous carcinoma among 455 cases of invasive carcinoma. On microscopy, tumor was composed of moderately differentiated adenocarcinoma

\section{Original Research Article}

and keratinizing squamous cell carcinoma. These tumors have been stated to have poor prognosis.

\section{Conclusion}

Cervical cancer continues to be the most common cancer of females in developing countries. One of the most significant advances in the management of cervical neoplasms has been the realization that cervical intraepithelial lesions behave as progressive stages of a biologic continuum towards the development of invasive cancer.

Author contribution: All authors contributed in planning, implementation, conduction of the study. All authors had equally contributed in preparation of manuscript.

Funding: Nil; Conflict of Interest: None initiated Permission from IRB: Yes

\section{References}

1. GLOBOCAN 2008 (IARC), Section of Cancer Information (8/10/2012). WHO 2009b; GLOBOCAN 2002 database: IARC.

2. Anderson MC. The etiology of cervical cancer. Female Reproductive System in Systemic Pathology. 3rd ed., Vol 6 New York: Churchill Livingstone; 1991: 76-9.

3. Wells M, Ostor AG, Crum CP, Franceschi S, Tommasino M, Nesland JM, et al. Epithelial tumours. In: Tavassoli FA, Devilee P, editors. World Health Organisation classification of tumours. Pathology and genetics of tumours of the breast and female genital organs. Lyon: IARC Press-2003.p.262-79.

4. Akhter S, Bari A, Hayat Z. Variability study between Pap smear, Colposcopy and Cervical Histopathology findings. J Pak Med Assoc. 2015;65(12):1295-9.

5. Mehta A, Ladola H, Kotadiya K, Edwin R, Patel V, Patel V. Study of high risk cases for early detection of cervical cancer by PAP's smear and visual inspection by Lugol's Iodine Method. NHL J Medical Sciences. 2013; 2(1):65-8.

6. Atla BL, Uma P, Shamili M, Kumar S. Cytological patterns of cervical pap smears with histopathological correlation. Int J Res Med Sci. 2015;3(8):1911-6.

7. Sharma A, Rajappa M, Saxena A, Shamla M. Telomerase activity as a tumour marker in Indian women with cervical intraepithelial neoplasia and cervical cancer. Mol Diag Ther 2007;11(3):193-201. 
8. Sherman ME, Wang SS, Tarone R, et al. Histopathologic extent of cervical intraepithelial neoplasia 3 lesions in the atypical squamous cells of undetermined significance low-grade squamous intraepithelial lesion triage study: implications for subject safety and lead-time bias. Cancer Epidemiol Biomarkers Prev. 2003 Apr;12(4):372-9.

9. Solapurkar ML. Histopathology of uterine cervix in malignant and benign lesions. J Obstet Gynaecol India 1985; 35:933-7.

10. Momtahen S, Kadivar M, Kazzazi AS, et al. Assessment of gynecologic malignancies: a multi-center study in Tehran (1995-2005). Indian J Cancer. 2009 JulSep; 46 (3): 226-30. doi: 10. 4103/ 0019-509X. 52957.

11. Chhabra S, Bhavani M, Mahajan N, et al. Cervical cancer in Indian rural women: trends over two decades. J Obstet Gynaecol. 2010;30(7):725-8. doi: 10.3109/ 01443615. 2010.501412.

12. Lowe D, Jorizzo J, Chiphangwi J, Hutt MS. Cervical carcinoma in Malawi: a histopathologic study of 260 cases. Cancer. 1981 May 15;47(10):2493-5.

\section{Original Research Article}

13. Scarinci $\mathrm{IC}^{1}$, Garcia FA, Kobetz E, et al. Cervical cancer prevention: new tools and old barriers. Cancer. 2010 Jun 1;116(11):2531-42. doi: 10.1002/cncr. 25065 .

14. Chen J, Macdonald K, Gaffney DK. Incidence, mortality, and prognostic factors of small cell carcinoma of the cervix. ObstetGynecol 2008; 111: 13 94-402.

15. Maiman MA, Fruchter RG, DiMaio TM, et al. Superficially invasive squamous cell carcinoma of the cervix. Obstet Gynecol. 1988 Sep;72(3 Pt 1):399-403.

16. van Nagell JR Jr, Greenwell N, Powell DF, et al. Microinvasive carcinoma of the cervix. Am J Obstet Gynecol. 1983 Apr 15;145(8):981-91.

17. Hurt WG, Silverberg SG, Frable WJ, et al. Adenocarcinoma of the cervix: histopathologic and clinical features. Am J Obstet Gynecol. 1977 Oct 1;129 (3): 304-15.

18. Zanetta GM, Gostout BS, Kerney GL, Lee R.A. An unusual presentation of cervical adeno-squamous carcinoma. J Pelvic Surg 1999; 5(3):171-4.

\section{How to cite this article?}

Supriya B.R, Patel R, Patel M. Histopathological evaluation of Non-Neoplastic and Neoplastic Lesions of Uterine Cervix at tertiary care centre. Trop J Path Micro 2019;5(3):177-182.doi:10.17511/jopm.2019.i03.11. 